\title{
An Invitation for Medical Educators to Focus on Ethical and Policy Issues in Research and Scholarly Practice
}

\author{
Laura Weiss Roberts, MD, Cynthia Geppert, MD, MA, Renee Connor, Khanh Nguyen, MS, \\ and Teddy D. Warner, PhD
}

\begin{abstract}
\begin{tabular}{|l|l}
\hline & ABSTRACT \\
\hline
\end{tabular}
Medical education research and medical education practice both involve being methodical, innovative, self-observing, forward-looking, and open to peer review, and both are scholarly activities. For these reasons, distinguishing between these two activities is often difficult. There are three important reasons to clarify the distinctions: the moral difference between education research and education practice; federal regulations governing education research that require more safeguards than often exist in education practice; and the fact that student participants in research have characteristics in common with members of special populations.

The authors explain why attention to issues of safeguards in education research and practice is likely to grow at academic health centers, yet maintain that these issues are neglected in the medical education literature. They demonstrate this with findings from their review of 424 education research reports published in 1988 and 1989

and in 1998 and 1999 in two major medical education journals. Each article was evaluated for documentation of six ethically important safeguards and features (e.g., informed consent). The rates of reporting the six features and safeguards were relatively low $(3-27 \%)$. Nearly half (47\%) of the empirical reports offered no indication of ethically important safeguards or features, and no article mentioned all six. Furthermore, those rates did not increase substantially after ten years. The authors discuss a number of implications of their findings for faculty, training institutions, students, and editors and peer reviewers, and conclude with the hope that their findings will raise awareness of these neglected issues in medical education and will stimulate all those involved to reflect upon the issues and set standards on the ethical aspects of research and scholarly practice.

Acad. Med. 2001;76:876-885.
\end{abstract}

\section{Question}

When does scholarly education practice end, and when does education research begin?

Dr. Roberts is associate professor, vice chair for administration, and director, Empirical Ethics Group (EEG), Department of Psychiatry, University of New Mexico School of Medicine (UNMSOM); Dr. Geppert is a third-year resident and research fellow, Department of Psychiatry, UNMSOM; Ms. Connor is a nursing student at the University of New Mexico School of Nursing and project coordinator, EEG, Department of Psychiatry, UNMSOM; Mr. Nguyen is a statistician, EEG, Department of Psychiatry, UNMSOM; and Dr. Warner is research assistant professor and associate director, EEG, Department of Psychiatry, UNMSOM.

Correspondence and requests for reprints should be addressed to Dr. Roberts, Associate Professor and Vice Chair for Administration, Department of Psychiatry, University of New Mexico School of Medicine, 2400 Tucker NE, Albuquerque, NM 87131-5326.

For another article on a related topic, see page 871.
A. A teacher tries out a new approach in the classroom and

likes it.

B. A teacher tries out a new approach in the classroom, likes it, and seeks feedback from students.

C. A teacher tries out a new approach in the classroom, likes it, seeks feedback from students, compares classroom performance data from last year and this year, and tells colleagues casually about it.

D. A teacher tries out a new approach in the classroom, likes it, seeks feedback from students, compares classroom performance data from last year and this year, and tells colleagues about it formally in a department meeting.

E. A teacher tries out a new approach in the classroom, likes it, seeks feedback from students, compares classroom performance data from last year and this year, tells colleagues about it formally in 
a department meeting, and prepares an institutional Web site on the new approach.

F. A teacher tries out a new approach in the classroom, likes it, seeks feedback from students, compares classroom performance data from last year and this year, tells colleagues about it casually and in a department meeting, prepares a Web site on the new approach for interested colleagues, and prepares a descriptive poster, including data analyses, for a regional education conference.

G. A teacher tries out a new approach in the classroom, likes it, seeks feedback from students, compares classroom performance data from last year and this year, tells colleagues about it, prepares a Web site on the new approach for interested colleagues, prepares a descriptive poster, including data analyses, for a regional education conference, and the following year, prospectively randomizes students into two groups-those taught by the traditional approach and those taught by the new approach, evaluates performance data, and presents her findings in a peer-reviewed paper in an esteemed national education journal.

Answer 1: By tradition in medical education, A-F may be viewed as scholarly education practice, although many would see $F$ as research and most would agree that $G$ certainly represents an educational research endeavor.

Answer 2: By federal human research regulations, $A$ and $B$ represent scholarly education practice, C, D, and E may be held to federal human research standards (depending on the intent of the teacher/ researcher), and $F$ and $G$ definitely are subject to federal human research standards (e.g., mandatory institutional review board review or formal exemption, demonstrable confidentiality safeguards).

Human research is defined in U.S. federal regulations as the study of living human beings with the intent to contribute to generalizable knowledge. ${ }^{1}$ Investigation in medical education is systematic inquiry focusing on students, curricular initiatives, or training processes in an effort to foster the goals of learners and learning in medicine. Scholarly practice of medical education involves creating, implementing, and evaluating educational approaches to help students. ${ }^{2}$ Academically rigorous medical education practices, furthermore, require that teachers openly place their work before their colleagues for consideration and scrutiny. ${ }^{3}$ Taken together, medical education research and medical education practice both involve being methodical, innovative, self-observing, forward-looking, and open to peer review. Moreover, both are scholarly activities aimed ultimately toward the benefit of others. For these reasons, the distinction between education research and practice is often not clear.

This lack of clarity would be merely an issue for philosophical debate were it not for three key considerations. First, there is a critical moral difference between education research and scholarly education practice: in investigation, the researcher's primary aim is the advancement of a field of scientific knowledge, whereas in education, the teacher's primary aim is the advancement of his or her students' knowl- edge, skill, and capacities. In education research, an individual student participant's best interests may on occasion be subordinated to achieve a larger scientific objective. In scholarly education practice, however, the teacher has an ethical duty to foster the learning of students to the best of the teacher's ability at all times-even when implementing curricular change or trying a new teaching technique. The teacher may inadvertently compromise the learning experience of students-for example, when an innovation poses unforeseen problems - but the fundamental intent should always be to better the learning process.

This leads to the second consideration: education research is governed by federal regulations requiring more rigorous safeguards than often exist in usual education practice. Education research is subject to institutional review board (IRB) oversight when conducted at institutions that receive federal funding (see List 1). The chair of the IRB may require that some education research protocols undergo full formal committee review, be revised to minimize psychosocial risks, and incorporate written informed consent processes. The process of data collection, review, and analysis, moreover, must have explicit confidentiality procedures to protect the privacy of study volunteers. In contrast, scholarly education practice is typically not subject to specific federal regulations in the same manner. Education activities are governed through respect for the values of local leadership, institutional procedures, guidelines of accrediting bodies and professional organizations, broad federal policies (e.g., the Americans with Disabilities Act), and case law. ${ }^{4-6}$ Consequently, oversight of education research is a clear compliance issue for an academic health center, whereas supervision of educational practices is more a matter of institutional culture.

Third, it is increasingly recognized that students who participate in research have several characteristics in common with members of special populations. Medical trainees, for instance, resemble institutionalized populations in that they may feel relatively captive and powerless in the small community of a medical school, where they may have overlapping roles as students, as study participants, and even as patients. ${ }^{7,8}$ When sensitive information pertaining to student participants (e.g., academic performance, race-ethnicity and socioeconomic status, debt burden, health data, substance use) is collected by faculty who give grades to students, write their letters of recommendation, and influence their future careers, the potential risks of education research are dramatically increased. ${ }^{9}$ Because students are trained in settings with active clinical and education research enterprises, they may be especially likely to be approached to enroll in studies and may feel they must participate when invited by their faculty. Furthermore, because many students have few financial resources, they may be more likely to be influenced 


\section{List 1}

\section{Information from Federal Regulations Applicable to Education Research*}

Definition of Research

Research means a systematic investigation, including research development, testing, and evaluation, designed to develop or contribute to generalizable knowledge. Activities which meet this definition constitute research for purposes of this policy, whether or not they are conducted or supported under a program which is considered research for other purposes. For example, some demonstration and service programs may include research activities. (45 CFR 46, Subpart A, Sec. 46.102)

\section{Definition of Human Participant}

A living individual about whom an investigator (whether professional or student) conducting research obtains (1) data through intervention or interaction with the individual or (2) identifiable private information. (45 CFR 46, Subpart A, Sec. 46.102)

\section{Relevant Guidelines for Oversight by Institutional Review Boards}

(Minimal risk) research involving the collection and study of existing data, documents, records, pathological specimens or diagnostic specimens is subject to expedited review. This stands if these sources are publicly available or if the information is recorded by the investigator in such a manner that subjects cannot be identified, directly or through identifiers linked to subjects. (45 CFR 46, Subpart A, Sec. 46.101)

(Minimal risk) research involving the use of educational tests (cognitive, diagnostic, aptitude, achievement), survey procedures, interview procedures, or observation of public behavior is exempt from regulation unless: (1) information obtained is recorded in such a manner that human subjects can be identified, directly or through identifiers linked to the subjects; and (2) any disclosure of the human subjects' responses outside the research could reasonably place the subjects at risk for criminal or civil liability or could be damaging to the subjects' financial standing, employability, or reputation. (45 CFR 46, Subpart A, Sec. 46.101)

(Minimal risk) research conducted in established educational settings, involving normal education practices such as (1) research on regular and special education instructional strategies, or (2) research on the effectiveness of or the comparison among instructional techniques, curricula, or classroom management methods are exempt from coverage by federal regulations. (45 CFR 46, Subpart A, Sec. 46.101)

* Department of Health and Human Services, National Institutes of Health, Office of Protection from Research Risks. Code of Federal Regulations, Title 45: Public Welfare. Part 46: Protection of Human Subjects. Washington, DC: Department of Health and Human Services, 1991.

strongly by even modest incentives. ${ }^{10,11}$ These pressures may undermine students' capacity for authentic voluntarism when considering whether or not to participate in a research study, thus interfering with true informed consent for these individuals. ${ }^{12}$ As in other institutional settings, such forces increase the vulnerability of research participants and interfere with safeguards constructed to protect them in ethical scientific endeavors. ${ }^{13}$

The salience of these issues pertaining to education research and scholarly practice is likely to grow for faculty at academic health centers, for several reasons. On a federal level, the Office for Human Research Protections (formerly the Office for Protection against Research Risks) has indicated that regulatory oversight of behavioral, social scientific, and education research will become more rigorous in coming years, paralleling the process of tightening the supervision of biomedical research in this country. ${ }^{14} \mathrm{~A}$ second consideration that increases the significance of these issues is that education-related data are increasingly gathered for a variety of purposes at academic health centers. This trend is likely to continue as these institutions place greater emphasis on measuring outcomes of innovative education programs, on assessing achievement of learners in predefined competence areas, and on using education-related data in evaluating performances of faculty. ${ }^{15}$ Data-driven approaches to computing education productivity and impact, analogous to "continuous quality improvement" efforts in the clinical realm, will become a new standard in education practice for academic health centers. ${ }^{16}$ As these data are shared through Web sites and other electronic media directed toward institutional colleagues but accessible to the general public, the difference between education research and scholarly education practice will be even more difficult to determine, because the intent to contribute to generalizable knowledge will be a less distinguishing feature. Taken together, these trends will create new ethical complexities for academic medical faculty and daunting regulatory compliance problems for their home institutions in this country. 


\section{A Neglected Consideration}

The research report is a document not only for the scientific community, but also for the society that makes science possible at all.-J. C. FLETCHER ${ }^{17}$

The ethical and policy issues surrounding education research and scholarly practice have received little attention in the medical education literature despite their importance for academic medical education and the larger context of human research. ${ }^{8}$ By way of illustration, we performed an extensive literature search utilizing Medline and Psych-Info databases and found only three articles specifically addressing the topic of ethical safeguards for medical students as research subjects. ${ }^{8,18,19}$ In reading empirical reports in medical education journals, furthermore, it has been our sense that these issues are seldom discussed and poorly understood.

\section{Our Review of Education Research Reports}

To confirm or refute this impression, we sought to assess the degree to which ethically important features and safeguards undertaken to protect the interests of student participants are documented in education research reports. We hypothesized that ethically important safeguards and features such as review by an IRB or an education committee, confidentiality protections, informed consent processes, incentives for participation, and source of research funding would rarely be mentioned in published education research. We further hypothesized that these six features and safeguards would not be documented with much greater frequency now than they were ten years ago.

We reviewed every article from two major medical education journals, Medical Education and Academic Medicine (or its predecessor, the Journal of Medical Education), published in the years 1988 and 1989 and ten years later in 1998 and 1999. We assessed only those articles with explicitly defined methods sections and those that reported studies whose participants included premedical students, medical students, or residents. Studies involving only practicing physicians and other allied health professionals as participants were excluded. The instructions for authors of both journals were also reviewed.

In the quantitative component of the study, each article was individually evaluated for any form of documentation of six ethically important safeguards and features. Three of these were informed consent, confidentiality, and IRB review. We also looked for any indication that an education committee had approved the research endeavor, which is evidence of a traditional education safeguard. Finally, we looked for documentation of incentives offered to participants and for the funding source of the study. We selected these six ethical features and safeguards based on a literature review and a similar study performed by one of us (LWR) previously. ${ }^{20}$ For this project, if an article made mention of a particular feature or safeguard, regardless of whether or not it was performed, a presence-of-documentation score was recorded. Otherwise, an absence-of-documentation score was given. On these items, inter-rater reliability between the two raters was performed on a subset of 24 articles, i.e., three articles selected randomly from each journal for each of the four years examined in the study. Interrater reliabilities (Cohen's kappa coefficient) ranged from 0.70 to 1.00 , average 0.92 .

In the qualitative review, key themes were identified and then discussed. Articles that had clear and complete documentation of ethical safeguards were noted, as were articles that described studies with significant psychosocial risks for student participants, had incomplete documentation of ethical safeguards, or revealed unusual practices (e.g., deception of student participants).

\section{What We Found}

We identified 424 empirical articles, 170 from Medical Education and 254 from Academic Medicine. A total of 106 were published in 1988, 68 in 1989, 112 in 1998, and 137 in 1999.

As hypothesized, the rates of reporting the six ethically important features and safeguards related to the potential ethical conduct of the works described in the publications were relatively low (Table 1). Overall, $27 \%$ mentioned the source of funding for the study; $23 \%$ mentioned informed consent; $22 \%$ mentioned participant confidentiality; $5 \%$ mentioned an incentive payment; $3 \%$ mentioned the IRB; and $3 \%$ mentioned involvement of an education committee. Nearly half $(47 \%)$ of the empirical reports offered no indication of any of these features or safeguards. Thirty-one percent mentioned one, 16\% mentioned two, and 6\% mentioned three or more. No single article documented all six of the elements we sought.

In support of our second hypothesis, we found that the rates of reporting ethically important features or safeguards did not increase substantially over the time frame of publication of the journals we evaluated. To test this hypothesis, we cross-tabulated each feature and safeguard (reported versus not reported) against the years of the publication (19881989 versus 1998-1999) and computed a Fisher's exact statistic for each. All six of them showed small changes in reporting rates over the decade, with increases ranging from $2 \%$ to $7 \%$. Only two of the features and safeguards (IRB, $p$ $=.02$; education committee review, $p=.03$ ) showed statistically significant increases. Another one, confidentiality protection, approached significance $(p=.09)$. A weak but significant positive correlation between decade of publica- 
Table 1

\begin{tabular}{|c|c|c|c|c|}
\hline \multicolumn{5}{|c|}{$\begin{array}{l}\text { Ethically Important Features and Safeguards Mentioned in Tu } \\
\text { Medical Education Journals, 1988-1989 and 1998-1999* }\end{array}$} \\
\hline \multirow{2}{*}{$\begin{array}{c}\text { Features/Safeguards Sought } \\
\text { in the Journal Articles } \\
\text { Reviewed } \dagger\end{array}$} & \multicolumn{3}{|c|}{$\begin{array}{l}\% \text { Articles That Mentioned } \\
\text { Feature/Safeguard }\end{array}$} & \multirow[b]{2}{*}{$p \ddagger$} \\
\hline & $1988-89$ & 1998-99 & Overall & \\
\hline \multicolumn{5}{|l|}{ Informed consent } \\
\hline Academic Medicine & 17.8 & 21.4 & 19.8 & 0.52 \\
\hline Medical Education & 26.9 & 28.1 & 27.6 & 0.85 \\
\hline Total & 21.3 & 24.2 & 22.9 & 0.56 \\
\hline \multicolumn{5}{|l|}{ Confidentiality } \\
\hline Academic Medicine & 20.6 & 22.1 & 21.3 & 0.88 \\
\hline Medical Education & 12.1 & 28.1 & 21.9 & 0.01 \\
\hline Total & 17.3 & 24.6 & 21.5 & 0.09 \\
\hline \multicolumn{5}{|l|}{ Institutional review board } \\
\hline Academic Medicine & 0.9 & 7.5 & 4.7 & 0.02 \\
\hline Medical Education & 0.0 & 0.0 & 0.0 & 1.00 \\
\hline Total & 0.6 & 4.4 & 2.8 & 0.02 \\
\hline \multicolumn{5}{|l|}{ Education committee review } \\
\hline Academic Medicine & 0.0 & 2.7 & 1.6 & 0.14 \\
\hline Medical Education & 1.5 & 5.8 & 4.1 & 0.25 \\
\hline Total & 0.6 & 4.0 & 2.6 & 0.03 \\
\hline \multicolumn{5}{|l|}{ Incentive to participate } \\
\hline Academic Medicine & 2.8 & 9.6 & 6.7 & 0.04 \\
\hline Medical Education & 4.5 & 2.9 & 3.5 & 0.68 \\
\hline Total & 3.4 & 6.8 & 5.4 & 0.19 \\
\hline \multicolumn{5}{|l|}{ Funding source for study } \\
\hline Academic Medicine & 29.2 & 32.4 & 31.3 & 0.67 \\
\hline Medical Education & 19.4 & 21.4 & 20.6 & 0.84 \\
\hline Total & 25.4 & 27.8 & 27.4 & 0.65 \\
\hline \multicolumn{5}{|c|}{$\begin{array}{l}\text { *The authors documented the presence of six ethically important features and } \\
\text { safeguards related to the studies described in articles in two medical education } \\
\text { journals. }\end{array}$} \\
\hline \multicolumn{5}{|c|}{$\begin{array}{l}\text { †Subsample sizes, by journal: Academic Medicine, } n=254 \text {; Medical Education, } \\
n=170 \text {. Subsample sizes by years: } 1988-1989, n=175 ; 1998-1999, n=249 \text {. }\end{array}$} \\
\hline $\begin{array}{l}\ddagger \text { ‡y Pearson's } \chi^{2} \text { or Fisher's exac } \\
\text { by years by journal. }\end{array}$ & test (two-tai & d), the prob & bility of dif & erences \\
\hline
\end{tabular}

tion and number of features or safeguards reported was found $(r=0.11, p=.02)$.

To determine whether reporting rates generalized across the two journals, we conducted a series of six three-way cross-tabulations of outcome by years by journal. For three measures (confidentiality, $p<.01$; IRB approval, $p=.02$; and documentation of incentive, $p<.05)$ the effects of the difference of a decade depended upon the journal. Specifically, in contrast to Medical Education, Academic Medicine showed statistically significant increases in the mention of IRB ( $+7 \%$ for Academic Medicine versus $0 \%$ for Medical Education) and in the mention of incentives ( $+7 \%$ for Academic Medicine versus $-2 \%$ for Medical Education). On the other hand, Medical Education showed a reliable increase in the reporting of confidentiality, while Academic Medicine did not $(+16 \%$ for Medical Education versus $+2 \%$ for Academic Medicine).

Beyond these quantitative findings, three of us independently examined the articles for their thematic content and for examples of sufficient and insufficient reporting of ethically important features or safeguards. We did not assess the studies for indications of ethical misconduct, nor did we draw this conclusion based on any of the published reports. Several papers provided documentation of clear attentiveness to ethical considerations. For instance, several studies looked at symptoms of mental illness, illicit drug use, smoking, or alcohol and caffeine consumption. The authors of these reports provided clear documentation of IRB approval, confidentiality protections, and other safeguards. In some of the studies that investigated learning styles, the use of standardized patients, or new teaching interventions, it was noted that participation was voluntary, informed consent was obtained, confidentiality was protected, and incentives were specified.

In contrast, many articles offered little documentation given the nature of the inquiry reported. For example, reports of studies in which personality, psychometric, and other psychological instruments were administered to medical students and residents often provided no indication of safeguards employed. Some articles in which potentially sensitive data (e.g., loan indebtedness, HIV exposure, scores on the Medical College Admission Test, grade-point averages, ethnicity, gender, age, or number of repeat exams) were reported made no mention of confidentiality or IRB mechanisms - protections that would ordinarily be necessary according to current federal regulations. Some reports of prospectively planned experimental studies indicated that participation was "mandatory" or "required," raising the issue of whether adequate consent processes were in place. Similarly, other reports described how surveys and questionnaires also were administered during class time for research purposes, sometimes in place of a regularly scheduled quiz. In one report, it was documented that student participants were purposely not told that they were involved in a study. In another report, it was clearly noted that student participants were explicitly misinformed about the true purpose of the research endeavor.

The findings reported above indicate that relatively little documentation regarding ethically important features and safeguards exists in empirical reports published a decade apart in two major medical education journals. These quan- 
titative findings are similar to those obtained in an analogous study performed by one of us (LWR) with others, in which only $23 \%$ of published reports in the geriatrics literature mentioned informed consent and 5\% mentioned IRB approval. ${ }^{10}$ Qualitative review of the empirical reports revealed significant variability in documentation, with some authors providing detailed descriptions of safeguards and other authors offering essentially no information.

There were some limitations to our study. Our method did not provide a direct, accurate measure of the presence or absence of the six features and safeguards as they were actually conducted in the education projects. Our method also did not assess the authors' intent in terms of reporting academic activities that were simply "education scholarship" as opposed to formal "education research." Finally, our approach could not measure whether ethical dimensions of research were explicitly addressed in cover letters to editors and reviewers at the time of manuscript submission, a practice consistent with the recommendations in both journals' instructions for authors.

\section{IMPLICATIONS AND RECOMMENDATIONS}

Ethically sound education research and scholarly practice activities in medical education both hinge on the integrity of academic medical faculty and a culture of respect within medical schools and teaching hospitals. That these endeavors are being carried out with professionalism is an expectation fundamental to the public trust in medicine in our country. ${ }^{21}$ Our conceptual and empirical analyses suggest that we, as a community of medical educators, face a serious problem in living up to the emerging standards of ethics and accountability in human research at this point in our history. On conceptual grounds, it appears that the lack of clarity of the distinction between education research and scholarly practice activities within the traditions of our academic health centers is such that we may not build in adequate safeguards for our students. On empirical grounds, it appears that we do not demonstrate our attentiveness to ethical considerations in evidence-based reports in the medical education literature. This conceptual and empirical analysis has potential repercussions for four groups-academic faculty, institutions, students, and editors and peer reviewers-involved in medical training (List 2).

\section{Implications for Faculty}

We wish to highlight two kinds of ethically important issues that our findings raise for medical school faculty who teach and perform education research. The first pertains to role conflicts inherent in the teacher-researcher model, and the second relates to regulatory safeguards and investigator compliance issues.

Inherent role conflicts. Role conflicts are inevitable for the teacher who is also an education researcher. A teacher's first responsibility is to foster the learning of individual students, whereas an education researcher's first responsibility is to examine a scientific question important to education. These two duties may often be compatible, and certainly both require that students be treated respectfully, but there are times when the two roles may be incongruent. Consider an example in which the best interests of individual students become secondary to the scientific inquiry process. A clerkship director oversees two training sites and then elects to study the differential performances of the students in the two parts of the curriculum. The director's original aim, to advance the learning of all students rotating through the service, may then compete with a new goal of determining which elements of an educational context foster learning or, alternatively, pose barriers to learning. To render the data more interpretable and reliable, the teacher-education researcher may choose to assign students randomly to the two training sites, whereas in the past, acting solely as a teacher, the director would have placed students simply where they might learn best. In essence, the teacher who performs education research may end up in an ethical bind because he or she may be less able to respond to the needs of individual students and because students may believe that the teacher gives their interests and well-being first priority in making decisions about their training.

In a second example, the dual agency of the teacherresearcher generates another kind of ethical problem: how to protect confidentiality adequately when the faculty member gathers information in the context of research that may negatively bias his or her perspective toward students when serving in the teaching role. In this example, a clinical supervisor who works closely with students, evaluates their performance on the wards, and writes crucial letters of recommendation for residency programs also pursues research interests exploring risk factors for impairment in medical trainees. This scenario represents a natural overlap of interests, is probably not uncommon, and yet is highly complex from an ethical perspective because sensitive information revealed by students in the research context might make them vulnerable to discrimination if data were used inappropriately in the education context. ${ }^{7,22}$

In sum, while the dual role of the teacher and education researcher may be a source of insight and valuable innovation in medical education, there are potential role conflicts that require careful consideration. In this context, the usual respectful practices of teachers are not enough: more rigorous safeguards are necessary to protect the rights and well-being of student research participants. This is why regulations em- 


\section{List 2}

Recommendations, for Four Groups Involved in Medical Training, Regarding Ethically Sound Education Research and Scholarly Practice Activities

For academic medical faculty

Think carefully about your intent in creating and writing up an education-related activity. Is your intent strictly "educational"? Is your aim primarily "research" (i.e., the intent "to contribute to generalizable knowledge")? Is it a hybrid?

Become knowledgeable regarding federal and institutional human research guidelines; stay updated with these guidelines through continuing education and consultation.

Be aware of the dual roles you play as a teacher-researcher and know that these may create ethical conflicts. Seek consultation and guidance when problems arise. Separate the roles when possible.

Carefully consider the potential issues surrounding the source of funding for the project you wish to undertake.

Design studies that will present minimal risks of psychosocial harm to students.

Protect student participants' confidentiality carefully in the small community of the medical school.

Seek IRB or other formally arranged oversight processes (e.g., departmental or educational committee supervision) whenever student participants are involved.

Build in appropriate safeguards for student participants. For example,

recruit for student participants rather than making participation mandatory in all prospective education research;

provide an informed consent process with clear explanations of the purpose of the work and its potential risks, benefits, and alternatives;

create appropriate confidentiality measures for participants;

reassure potential student participants of the voluntary nature of participation and make sure that there are no ill consequences for non-involvement; and

offer compensation that is commensurate with effort and time and is not coercive.

Explicitly document ethically important features and safeguards in publications.

For training institutions

Foster a dialogue regarding the shared and distinct professional tasks associated with ethically sound education practice and education research

Develop and implement clear, rigorous protocols and policies regarding education research (e.g., selection, recruitment, and consent processes, IRB requirements, confidentiality, recruitment, appropriate incentives, and appropriate sources of research funding).

Implement strict confidentiality safeguards pertaining to use of demographic and performance-information databases.

Include students, educators, and education researchers as representatives in institutional review processes to help assess education research projects.

Develop and implement a mechanism of appeal for students who have ethical concerns regarding education research participation.

Develop and implement continuing coursework in education research ethics for academic medical faculty.

For students

Be aware of the potential concerns that may arise in research participation, including role conflicts, confidentiality, consent, and voluntarism issues; know your rights as a student and/or as a student participant in research.

Find out about how information regarding students is used by your medical training institution.

Support the involvement of students in the development of institutional policies related to teaching and education research activities.

Seek student representatives on education committees and your institution's IRB to address ethical issues that may arise.

If you perform research, become knowledgeable about your responsibilities as an investigator.

For editors and peer reviewers

Clarify the position of the journal regarding expectations of ethical conduct for researchers.

Communicate this position explicitly to prospective authors, reviewers, and readers.

Require documentation of ethically important features and safeguards in the body of the manuscript or, alternatively, in a cover letter accompanying the submission.

Obtain additional information and the review of an individual with ethics expertise when assessing empirical reports that present potential ethics problems. 
phasize institutional oversight, confidentiality, and consent to assure that the risks faced by participants are balanced by other considerations (e.g., scientific merit, potential benefits) and are undertaken in an informed and voluntary manner. These safeguards essentially mandate collaboration and shared decision making among the investigator, the institution, and the participant, thereby fulfilling the professional ethical principles governing human investigation outlined in the Belmont Report more than two decades ago: respect for persons; beneficence; and justice. ${ }^{23}$

Safeguard and compliance issues. The second implication for academic faculty pertains to regulatory safeguard and investigator compliance issues in human research. In understanding this set of issues, it is important to recognize that the procedures involved in education practice and in education research often overlap in medical training settings, thus creating considerable ambiguity for medical faculty. For instance, measuring students' performances on a standardized examination, assessing the impact of a new case format in a tutorial, determining the effectiveness of a computer simulator in teaching a physical diagnosis technique, conducting focus groups in evaluating curricular components, reviewing existing data on student achievement collected for other purposes (e.g., admission and promotion decisions), and documenting students' skills in an objective structured clinical examination are all examples of education-related activities that may be well within the scope of usual education practice at many medical schools and teaching hospitals but which also may be employed within educational research projects.

Consequently, federal regulations on safeguards in education research hinge largely on the teacher-researcher's intent at any given moment, rather than on the actual methods. If the faculty member's principal aim in implementing the educational endeavor, prospectively, is to contribute to generalizable knowledge, then, by definition, it is education research and thus subject to formal rules bearing upon human investigation. These rules require IRB exemption or expedited review, confidentiality protections, and in some cases formal consent processes. If, on the other hand, the principal aim of the activity is simply to teach students well, or better than in the past, then it may not meet the formal definition of human research. ${ }^{1}$ This is true even if a description of the work is later presented at a professional meeting or published in a journal, because those activities are congruent with accepted traditions of education scholarship. ${ }^{19}$ These traditions place responsibility for protecting the confidentiality of students upon the faculty member, for instance, but do not currently mandate IRB involvement or consent processes.

Adding to the ambiguity of this situation is the observation that the aim of carrying out an educational activity may change over time. What begins as the intuitive hunch of a teacher may ultimately become a highly sophisticated education innovation encompassing a strong research component and resulting in presentations or publications. In this case, the current interpretation of federal regulations governing human research suggests that the faculty member must monitor his or her motivation carefully. When the activity evolves so that its main focus shifts from teaching per se to data gathering with the intent to contribute to generalizable knowledge, the faculty member should put human research safeguards in place (e.g., seek IRB approval, confidentially encode data). Often very little documentation is maintained in parallel with this evolving process. This is a subtle business and, indeed, many find the issue of regulations based on intent or internal motivation-rather than on observable behavior-highly problematic. Yet, this is the circumstance in which we find ourselves. It is a situation that merits attention and guidance from our nation's community of medical educators.

\section{Implications for Training Institutions}

Taking direction from former President Clinton and the Office of the Secretary of Health, the Office for Human Research Protections has clearly articulated its intent to place increasing emphasis on safeguarding people, including student participants, from psychosocial risks of human investigation. ${ }^{24}$ Education, behavioral, and social scientific research domains have been specifically identified as requiring greater scrutiny. ${ }^{25}$ Education research activities involving medical students and other trainees will certainly receive careful attention. ${ }^{26}$ Adequacy of IRB processes (e.g., expertise and representation of committee members, appropriateness of documented risk assessments associated with specific protocols, and sufficiency of infrastructure support given institutional research volume) and of institutional policies related to research (e.g., operative definitions of education research and of recruitment, consent and confidentiality practices; and research use of existing education data) will be key elements of any such review. ${ }^{25}$ This is especially important in light of the development of clinician-educator tracks at many academic health centers and the emerging expectations for academic medical faculty to participate in education research for promotion. ${ }^{27}$ Academic health centers are entrusted with fostering excellence in biomedical education, research, and clinical care while also being responsible for overseeing the activities, interests, and well-being of their faculty, students, and patients. Without improved efforts to build education research policies and safeguards, and without greater consensus nationally regarding the application of regulations to education settings, medical training institutions may find themselves at heightened risk for federal inquiry. 


\section{Implications for Students}

There are several ethical and regulatory ramifications of the findings of the present study for student participants. For prospective research in education settings, for instance, informed consent may be very challenging. Many students may not be fully aware of certain aspects of research participation, such as the basic distinction between investigation and education, the institutional and regulatory protections afforded students, and the rights of student participants. Students whose teachers are also researchers may feel unable to decline participation in education studies, raising the question of whether authentic voluntarism is always possible. For instance, when a clerkship director asks students to be volunteers in an assessment of a new, experimental internal medicine curriculum, the students may be concerned about their evaluations if they refuse. ${ }^{28}$ Such students may feel coerced, even when no pressure is intended. For education research that involves retrospective use of existing data sets, many students may not understand that sensitive demographic information (e.g., loan indebtedness, health information) gathered by the institution may be used for projects. ${ }^{9}$ They may also be unaware of the fact that they are entitled to certain protections, ethically and legally (e.g., IRB oversight, removal of specific identifiers to assure confidentiality).

In both prospective and retrospective research endeavors, students' perceptions of the risk-to-benefit ratio of a project may be very different from that of faculty who are investigators or IRB members. ${ }^{28}$ Consequently, consent disclosure and institutional review processes may be adequate from a regulatory perspective but insufficient from the individual participant's viewpoint. Additional considerations relate to inappropriate use of convenience populations of students for research that might be better performed with other, less potentially vulnerable groups and to the appropriate use of incentives for students' participation. Student representatives on policymaking committees as well as on IRBs can help ensure that students' concerns are adequately safeguarded and can bring an important stakeholder perspective to discussions of the education and research missions of training institutions. ${ }^{18}$ Conscientious efforts to instruct and give greater voice to students as participants may help facilitate ethically acceptable research as standards evolve and become more rigorous in the future. ${ }^{28}$

\section{Implications for Editors and Peer Reviewers}

Editors and peer reviewers, as well as authors, share the obligation to ensure that publications reflect rigorous professional standards, scientifically and ethically. ${ }^{29}$ This dimension of scientific integrity originates from a key ethics principle, veracity. This is both a negative duty, i.e., to avoid fabrication, falsification, plagiarism, and other behaviors that are dishonest and undermine trust in the profession, and a positive duty, i.e., to behave honestly and to "seek and state the truth." This principle is at the heart of scientific practice, because only through accurate disclosure can others judge the true merit and meaning of the data obtained. It is also fundamental to ethical research because it allows for attention to moral dimensions of human investigation by researchers. As noted by Fletcher:

Failure to discuss how such crucial obligations and duties were met is morally injurious to a society that still generously supports ... investigation. A society that learns that its clear and highly valued obligations to human subjects are not even worth mentioning in a research report is justified in raising questions as to whether the ethical qualities of the conduct of the research match the report. ${ }^{17}$

It is clear that editors and peer reviewers in all areas of medicine are increasingly attentive to the ethical dimensions of the work they encounter. ${ }^{30}$ Nevertheless, our study revealed only a small increase in the pattern of documentation in the time frame we examined. While it is well established that empirical reports of medical education research should offer sufficient methodologic detail to allow the reader to assess the scientific caliber and interpretation of the findings presented, no analogous standard for ethical imperatives appears to exist in the medical education literature. Prospective authors and peer reviewers often receive relatively little concrete guidance from journals in terms of the conduct and presentation of human investigation, a concern that has been raised in other venues. ${ }^{17}$ This is especially relevant in areas such as medical education research, where the body of literature and shared understanding of ethical standards are not yet well developed. ${ }^{31}$

\section{The Need for Greater Awareness}

Inquiry to improve our understanding of learners and learning is fundamental to medical education. And yet, the process of inquiry poses distinct ethical and regulatory complexities that are seldom recognized. The traditions surrounding education research and scholarly practice are unclear, and as we report above, our empirical review revealed little documentation regarding ethically important features and safeguards in empirical reports published a decade apart in two medical education journals. We did not assess the conduct or ethical caliber of educational work described in the reports; we did not seek evidence of misconduct in medical education research, nor do we wish to suggest that we believe this to be a significant concern in this country. Nevertheless, it is our hope that our conceptual and 
empirical analyses will raise awareness of previously neglected issues in medical education and will serve as an invitation for medical faculty, leaders of training institutions, students, editors, and peer reviewers to engage in self-reflection, dialogue, and standard setting focusing on ethical aspects of research and scholarly practice.

\section{REFERENCES}

1. Department of Health and Human Services, National Institutes of Health, Office of Protection from Research Risks. Code of Federal Regulations, Title 45: Public Welfare. Part 46: Protection of Human Subjects. Subpart D, Additional Protections for Children Involved as Subjects in Research. Washington, DC: Department of Health and Human Services, 1991.

2. Gronlund NE. Assessment of Student Achievement. Boston, MA: Allyn and Bacon, 1998.

3. Glassick CE, Huber MT, Maeroff GI. Scholarship Assessed: Evaluation of the Professorate. San Francisco, CA: Jossey-Bass, 1997.

4. State of Georgia Professional Practices Commission. Code of Ethics for Educators: Georgia Association of Educators, 1999

5. Essex-Sorlie D. The Americans with Disabilities Act: II. Implications and suggestions for compliance for medical schools. Acad Med. 1994; 69:525-34.

6. Essex-Sorlie D. The Americans with Disabilities Act: I. History, summary, and key components. Acad Med. 1994;69:519-24.

7. Roberts L, Hardee JT, Franchini G, Stidley CA, Siegler M. Medical students as patients: a pilot study of their health care needs, practices, and concerns. Acad Med. 1996; 71:1225-32.

8. Howe KR. Ethics in educational research. Rev Res Educ. 1999; 24:2156.

9. Burgess RG. The Ethics of Educational Research. New York: Falmer Press, 1989.

10. Morrow D. Swallowing bitter pills or pay: the trials of guinea pigs. New York Times. Money and Business. September 26, 1996.

11. Roberts L. The ethical basis of psychiatric research: conceptual issues and empirical findings. Compr Psychiatry. 1998;39:99-110.

12. Roberts L. Informed consent and the capacity for voluntarism. Am J Psychiatry. 2000 [unpublished].

13. Brody JL, Gluck JP, Aragon AS. Participants' understanding of the process of psychological research: informed consent. Ethics and Behavior. 1997; 7:285-98.

14. Foubister V. New chief Dr. Koski gets tough on research standards. American Medical News. Government and Medicine. November 6, 2000
15. Meyer M, Genel M, Altman RD, Williams MA, Allen JR. Clinical research: assessing the future in a changing environment; summary report of conference sponsored by the American Medical Association Council on Scientific Affairs, Washington, DC. Am J Med. 1998;104: 264-71.

16. Gallin JI, Smits HL. Managing the interface between medical schools, hospitals, and clinical research. JAMA. 1997;277:651-4.

17. Fletcher JC. Ethical aspects of research involving elderly subects. J Clin Ethics. 1990:285-6.

18. Christakis N. Do medical student research subjects need special protection? IRB: A Review of Human Subjects Research. 1985;7:1-4.

19. Howe KR, Dougherty KC. Ethics, institutional review boards, and the changing face of educational research. Educ Researcher. 1993;22:1621.

20. Lane LW, Cassel CK, Bennett W. Ethical aspects of research involving elderly subjects: are we doing more than we say? J Clin Ethics. Winter 1990;1:278-85; discussion 285-6 [published erratum appears in J Clin Ethics. Spring 1991;2:4].

21. Institute of Medicine. Preserving Public Trust: Accreditation and Human Research Participant Protection Programs. Washington, DC: National Academy Press, 2001.

22. Oppenheimer K, Miller M, Forney P. Effect of history of psychological counseling on selection of applicants for residencies. J Med Educ. 1987; 62:504-8.

23. National Commission for the Protection of Human Subjects of Biomedical and Behavioral Research. The Belmont Report: Ethical Principles and Guidelines for the Protection of Human Subjects of Research. Washington, DC; Government Printing Office, 1979.

24. Department of Health and Human Services. Secretary Shalala bolsters protections for human research subjects. HHS News. May 23, 2000.

25. Cohen J. The Federal Perspective on IRBs. American Psychological Soc Observer. 1999:18-19.

26. Roberts L. Ethics of Research with Special Populations: Participant Perspectives. Paper given at a conference, "Protecting Human Subjects in Behavioral Research" at Tempe, AZ, March 1999, sponsored by the Office for Protection from Research Risks.

27. Levinson W, Rubenstein A. Mission critical-integrating clinicianeducators into academic medical centers. N Engl J Med. 1999;341:840_ 3.

28. Danziel JR. Students as research subjects: ethical and educational issues. Australian Psychologist. 1996;31:119-23.

29. Stephenson J. Medical journals turn gaze inward to examine process of peer review. JAMA. 1997;278:1389-91.

30. Rennie D. Freedom and responsibility in medical publication: setting the balance right. JAMA. 1998;280:300-2.

31. Uniform Requirements for Manuscripts Submitted to Biomedical Journals. International Committee of Medical Journal Editors. Med Educ. 1999;33:66-78. 